\title{
Tensile Strength and Durability of Bovine Dentin
}

Toshiko INOUE, Takashi MIYAZAKI and Fumio NISHIMURA Department of Oral Biomaterials and Technology, Showa University School of Dentistry, 1-5-8, Hatanodai, Shinagawa-ku, Tokyo 142-8555, Japan

Corresponding author, Toshiko INOUE; E-mail: inoue@dent.showa-u.ac.jp

Received October 13, 2006 /Accepted January 10, 2007

This study investigated the effects of thermal cycling on the tensile strength of dentin. Bovine dentin were divided into 10 groups, which were then subjected to various conditions: intact after preparation, thereby serving as a control; heating in boiling water for 45 minutes; 10,000 thermal cycles in water; 10,000 thermal cycles in PBS; storage in water at 5, 23, or $55^{\circ} \mathrm{C}$ for two weeks; and storage in PBS at 5,23 , or $55^{\circ} \mathrm{C}$ for two weeks. Subsequently, bovine dentin were trimmed into dumbbell-shaped specimens and the tensile test performed in distilled water at $37^{\circ} \mathrm{C}$. Mean tensile strengths were compared statistically by one-way ANOVA and Fisher's PLTD test $(\mathrm{p}<0.05)$. Fracture surfaces were observed by scanning electron microscopy, and reliability of the results was analyzed with Weibull distribution. Tensile strength did not significantly change after thermal cycling or storage in water and PBS at all temperatures tested (71.2-77.0 MPa) but decreased after treatment with boiling water $(65.5 \mathrm{MPa})$.

Keywords: Dentin, Tensile strength, Thermal cycling

\section{INTRODUCTION}

In clinical dentistry, it is immensely and critically important that dental materials have adequate strength and durability while in service. This is because for teeth and many dental materials, the oral environment is a harsh and severe one on many fronts: thermal changes ${ }^{1-4)}$, occlusion $^{5-7}$, mastication $^{8,9)}$, $\operatorname{acids}^{10,11)}$, and enzymes ${ }^{12,13)}$. Against this background, for the durability test of teeth and many composite resins, thermal cycling is typically employed to simulate the daily changes in oral cavity temperature as well as the thermal stress with which they must cope ${ }^{14)}$.

During thermal cycling, it is possible that deterioration of the dentin, tooth-composite bonds, and composite resins may occur. Water exposure is known to degrade tooth-composite bonds ${ }^{15-17)}$, cause composite resins to degrade over time in water ${ }^{18,19}$, exacerbate leaching out of components from composite resins and thereby cause restoration-tooth bonds to deteriorate.

However, information is scarce concerning the possible deterioration of dentin substrates during thermal cycling. Therefore, in this study, the hypothesis was that the mechanical properties of dentin might be affected by thermal cycling. During thermal cycling, specimens are stored in water. Since water lacks calcium and phosphate ions, any resulting dissolution of the minerals is thus assumed to be the demineralization of dentin ${ }^{20}$. Since demineralization damages dentin, adhesion durability is therefore accordingly affected. This is because it has been suggested that demineralization of dentin, which causes weakness, reduces the tensile strength of dentin.
To clarify the damaging effects of thermal cycling on the tensile strength of dentin substrates as well as to evaluate the latter's durability, this study was undertaken using bovine teeth. Furthermore, dumbbell-shaped specimens were used for tensile testing as they were reportedly useful for identifying defects easily ${ }^{21-27}$.

\section{MATERIALS AND METHODS}

\section{Materials}

Bovine lower central incisors were immediately extracted after sacrificing animals assumed to be 2 to 2.5 years old according to their dental age. Any fractured or poorly mineralized teeth were eliminated. The teeth were frozen within three hours of extraction and stored at $-12{ }^{\circ} \mathrm{C}$ in a freezer (221YS2, Hitachi Air Conditioning and Refrigeration, Tokyo, Japan) until use. Prior to specimen preparation, the teeth were defrosted by immersion in distilled water at room temperature for 30 minutes.

\section{Specimen preparation}

Schematic representation of the tensile test procedure is shown in Fig. 1. Dentin slabs of $1 \mathrm{~mm}$ thickness were cut from the bovine teeth using a low-speed cutting machine (Isomet, Beuhler, Lake Bluff, IL, USA). The slabs were sectioned from an area of mid-coronal dentin, $2.4-3.4 \mathrm{~mm}$ from the tooth surface running parallel to the growth line (Fig. 1A $)^{21,22,25-27)}$. A dentin slab was harvested from each tooth.

Dentin slabs from the bovine teeth were divided into 10 groups (Table 1), which were subjected to the following conditions: intact after preparation 

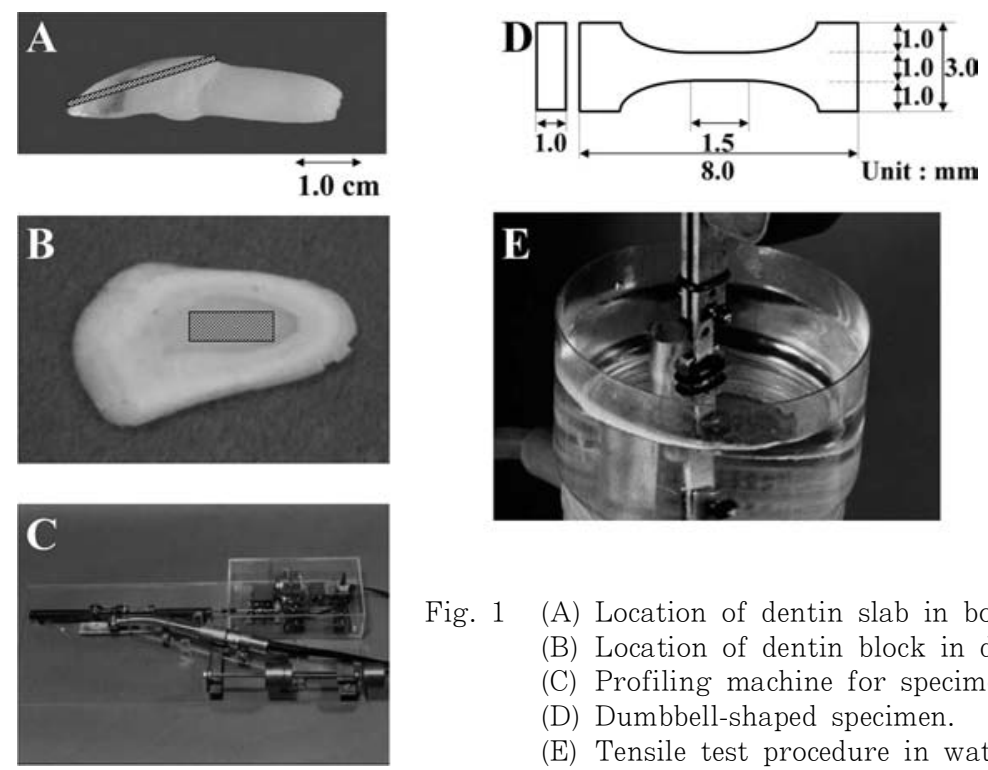

Fig. 1 (A) Location of dentin slab in bovine tooth.

(B) Location of dentin block in dentin slab.

(C) Profiling machine for specimen.

(D) Dumbbell-shaped specimen.

(E) Tensile test procedure in water.

Table 1 Experimental groups

\begin{tabular}{|c|c|c|c|}
\hline Group & Temperature & Duration & Solution \\
\hline 1 & +2 & 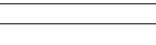 & 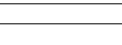 \\
\hline 2 & Thermal cycling & 2 weeks & Water \\
\hline 3 & Thermal cycling & 2 weeks & PBS \\
\hline 4 & $55^{\circ} \mathrm{C}$ & 2 weeks & Water \\
\hline 5 & $55^{\circ} \mathrm{C}$ & 2 weeks & PBS \\
\hline 6 & $23^{\circ} \mathrm{C}$ & 2 weeks & Water \\
\hline 7 & $23^{\circ} \mathrm{C}$ & 2 weeks & PBS \\
\hline 8 & $5^{\circ} \mathrm{C}$ & 2 weeks & Water \\
\hline 9 & $5^{\circ} \mathrm{C}$ & 2 weeks & PBS \\
\hline 10 & $100^{\circ} \mathrm{C}$ & 45 minutes & Water \\
\hline
\end{tabular}

(control, Group 1); 10,000 thermal cycles in water (Group 2); 10,000 thermal cycles in phosphate buffered saline (PBS) (Group 3); storage in water at $55^{\circ} \mathrm{C}$ (Group 4), $23^{\circ} \mathrm{C}$ (Group 6), or $5^{\circ} \mathrm{C}$ (Group 8) for two weeks; storage in PBS at $55^{\circ} \mathrm{C}$ (Group 5), $23^{\circ} \mathrm{C}$ (Group 7), or $5^{\circ} \mathrm{C}$ (Group 9) for two weeks; heating in a boiling water bath for 45 minutes (Group 10). Thermal cycling involved 10,000 cycles between a 55 ${ }^{\circ} \mathrm{C}$ water bath and a $5^{\circ} \mathrm{C}$ water bath, with a dwell time of one minute, and a transfer time of 10 seconds between baths. The 10,000 thermal cycles required two weeks. Similarly, Group 4-9 were immersed in a hot water bath $\left(55^{\circ} \mathrm{C}\right)$, a room temperature bath $\left(23^{\circ} \mathrm{C}\right)$, or a cold water bath $\left(5^{\circ} \mathrm{C}\right)$ for two weeks - the same storage duration as that required for 10,000 thermal cycles.

Two types of solution were used, water and physiological saline saturated with calcium and phosphorus. The PBS composition was $50 \mathrm{mmol} / 1$ HEPES buffer, $1.2 \mathrm{mmol} / 1 \mathrm{CaCl}_{2}, 0.72 \mathrm{mmol} / \mathrm{l}$ $\mathrm{KH}_{2} \mathrm{PO}_{4}$, and $30 \mathrm{mmol} / \mathrm{KCl}$, with a $\mathrm{pH}$ adjusted to 7.0 using $\mathrm{KOH}^{27)}$. For storage in $\mathrm{PBS}$, one dentin slab and $5.0 \mathrm{ml}$ of PBS were placed in $5.5 \times 5.5 \mathrm{~cm}$ pouches (HN-101, Asahi Kasei, Osaka, Japan), which were sealed with a vacuum packaging machine (SQ-202, Sharp, Osaka, Japan). For water immersion, 5-mm holes were created in the pouches to allow water in the water bath to come in contact with and circulate around the dentin slabs.

After preparation (control, Group 1) and storage (Groups 2-10), a rectangular block $(8.0 \times 3.0 \mathrm{~mm})$ was cut from the center of each dentin slab (Fig. 1B). By using a superfine diamond cutting bar (211SF, Shofu, Kyoto, Japan) and an air turbine handpiece (DA 231, Takara Belmont, Osaka, Japan) attached to a profiling machine (Fig. 1C), dumbbellshaped specimens with a narrow central portion, $1.0 \times 1.0 \times 1.5 \mathrm{~mm}$ (Fig. 1D), were harvested from each rectangular block of dentin slab. The profiling machine was used to create the dumbbell shape. As the specimen was moved by a motor, the guide roller moved along the template. The turbine head, which moved up and down, slid along the template. In this manner, uniformly shaped specimens were obtained. All surfaces of the central narrow portion were finished with 1200-grit wet silicon carbide paper 
under wet conditions s1-27). $^{21}$

Tensile test procedure

To test for tensile strength, the dentin specimens were mounted on a universal test machine (Model 1123, Instron Corp., Canton, MA, USA) using jigs. Distance between the upper and lower jigs was $4 \mathrm{~mm}$, and the crosshead speed was $0.5 \mathrm{~mm} / \mathrm{min}$. Tensile tests were performed in distilled water at a temperature of $37 \pm 0.5^{\circ} \mathrm{C}$ (Fig. 1E). Twenty specimens were employed for each test group. Mean tensile strength of the specimens was calculated for each of the 10 storage groups, and the results were statistically analyzed by one-way ANOVA and Fisher's PLSD test $(\mathrm{p}<0.05)$. Obtained tensile strengths were further analyzed using Weibull analysis, and the Weibull modulus and scale parameter of each group were calculated.

Scanning electron microscope (SEM) observation Fractured surfaces and side surfaces of the specimens were coated with gold using an ion sputtering machine (Ion Coater IB-3, Eiko Engineering Co., Tokyo, Japan) after the tensile tests. Then, the surfaces were observed by SEM (S-4500, Hitachi, Tokyo, Japan). Fracture origins were estimated from the observation of surface roughness gradation and crack running direction.

\section{RESULTS}

Tensile strength

The obtained tensile strengths are summarized in Fig. 2. The mean tensile strengths of the control (Group 1) and boiling condition group (Group 10) were 74.3 and $65.5 \mathrm{MPa}$, respectively. For the remaining conditions, tensile strength ranged from 71.2 to $77.0 \mathrm{MPa}$. In Groups $2-9$, the tensile strength of dentin remained unchanged during the two weeks of thermal stress. On the other hand, tensile strength decreased after treatment with boiling water $(65.5 \mathrm{MPa})$. One-way ANOVA revealed no significant differences in tensile strength among the remaining nine groups (excluding the boiling condition group, Group 10) .

Figure 3 shows the Weibull plot of the tensile strength of each group. Additionally, Weibull modulus and scale parameter obtained from the tensile strength of each group are shown in Table 2. Weibull moduli of the control (Group 1), water immersion groups (Groups 2, 4, 6, 8), PBS immersion groups (Groups 3, 5, 7, 9), and boiling condition group (Group 10) were 15.8, $7.7-11.0,9.0-18.9$, and 12.7 , respectively. The scale parameters of control, water immersion groups, PBS immersion groups, boiling condition group were 76.6, 75.679.0, $73.7-80.6$, and 68.1, respectively.

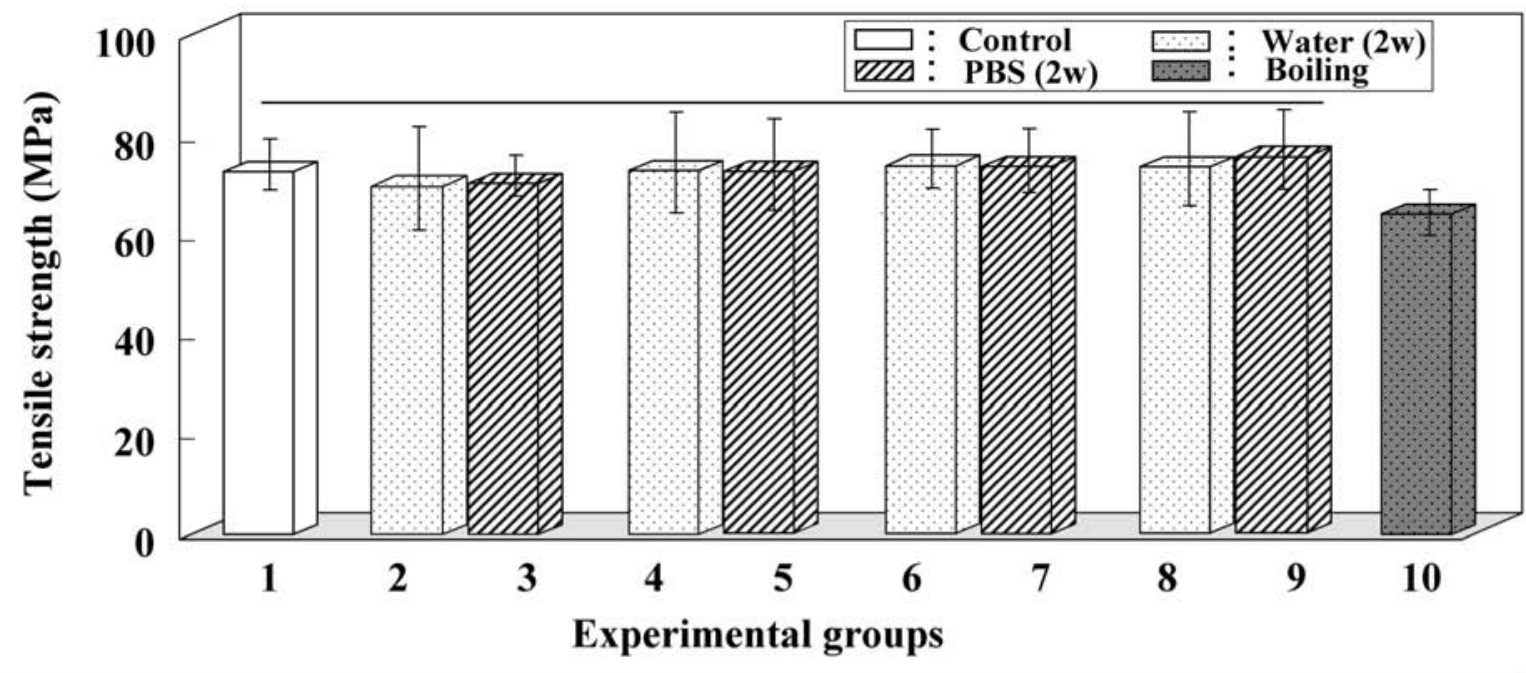

\begin{tabular}{crrrrrrrrrr}
\hline Mean & 74.3 & 71.2 & 71.8 & 74.4 & 74.0 & 75.2 & 75.1 & 74.8 & 77.0 & 65.5 \\
\hline SD & 5.1 & 10.3 & 4.1 & 10.0 & 9.1 & 5.9 & 6.4 & 9.5 & 8.0 & 4.6 \\
\hline
\end{tabular}

Fig. 2 Tensile strength of each group.

Vertical lines represent SD.

The horizontal line above the bars indicate groups that

do not differ statistically from each other $(\mathrm{p}>0.05)$. 


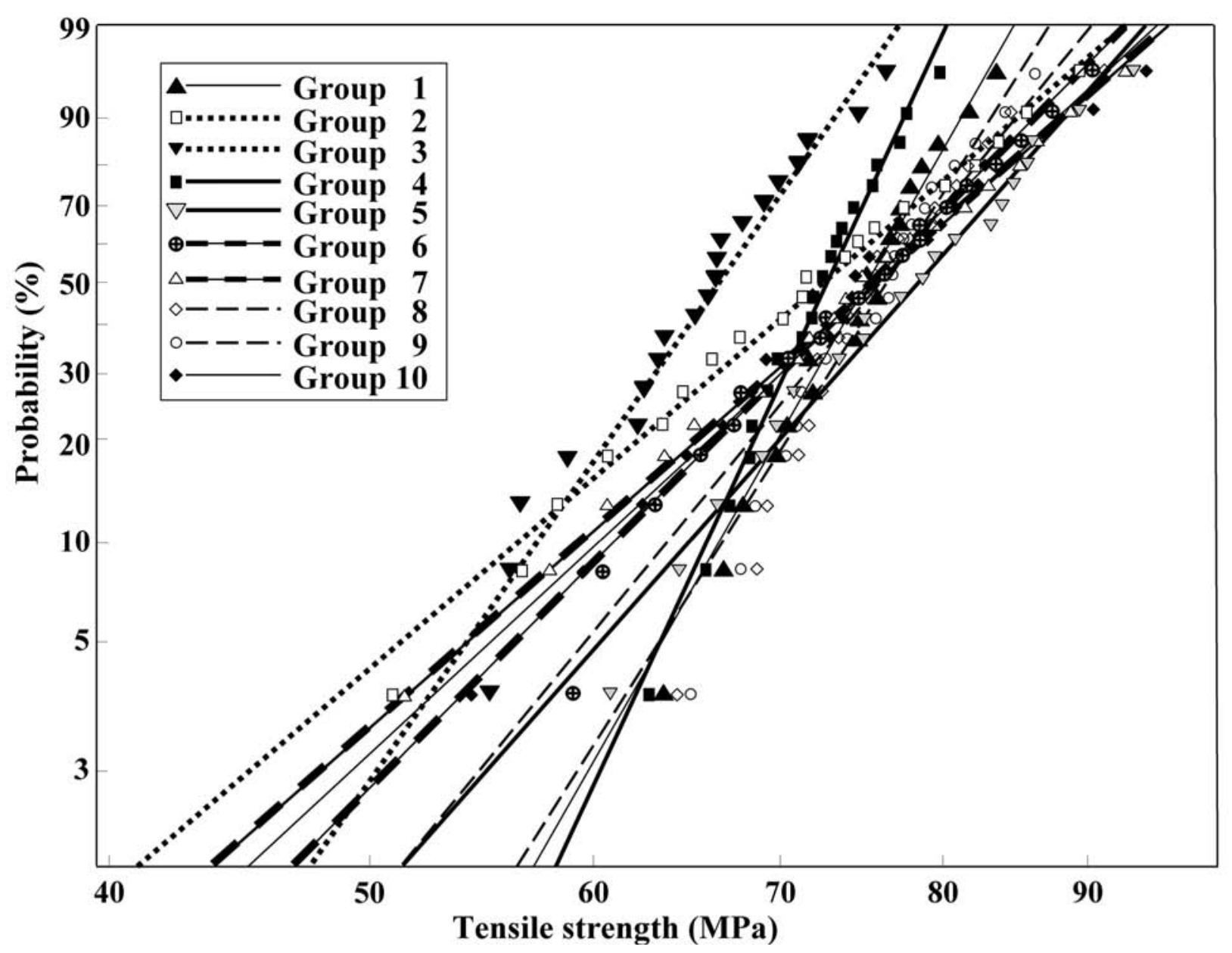

Fig. 3 Weibull plots of obtained tensile strength.

Table 2 Weibull moduli and scale parameters obtained from tensile strength for each group

\begin{tabular}{ccc}
\hline Group & Weibull modulus & Scale parameter \\
\hline 1 & 15.8 & 76.6 \\
2 & 7.7 & 75.6 \\
3 & 18.9 & 73.7 \\
4 & 7.9 & 78.7 \\
5 & 9.0 & 78.0 \\
6 & 11.0 & 78.0 \\
7 & 14.1 & 77.9 \\
8 & 8.2 & 79.0 \\
9 & 10.1 & 80.6 \\
10 & 12.7 & 68.1 \\
\hline
\end{tabular}

\section{SEM observations}

Typical fractured surfaces of Groups $1-9$ observed after the tensile strength test are indicated in Figs. 4A, 4B, and 4C. Fracture origins were also estimated from observations of surface roughness gradation and the crack running direction.

On the whole, the fractured surfaces appeared flat (Fig. 4A). A black arrow in Fig. 4A indicates the estimated fracture origin. The area indicated by the arrow in Fig. 4A is shown in Figs. $4 \mathrm{~B}$ and $4 \mathrm{C}$ under high magnification. Many dentinal tubules consisting of intertubular and peritubular dentin were observed on the fracture surface (Fig. 4B). As shown in Fig. 4C, the boundary between intertubular and peritubular dentin was distinguishable.

Figure 4D shows the dentin surface after heating in boiling water for 45 minutes. Denatured dentinal tubules were observed. As for the side surfaces of 

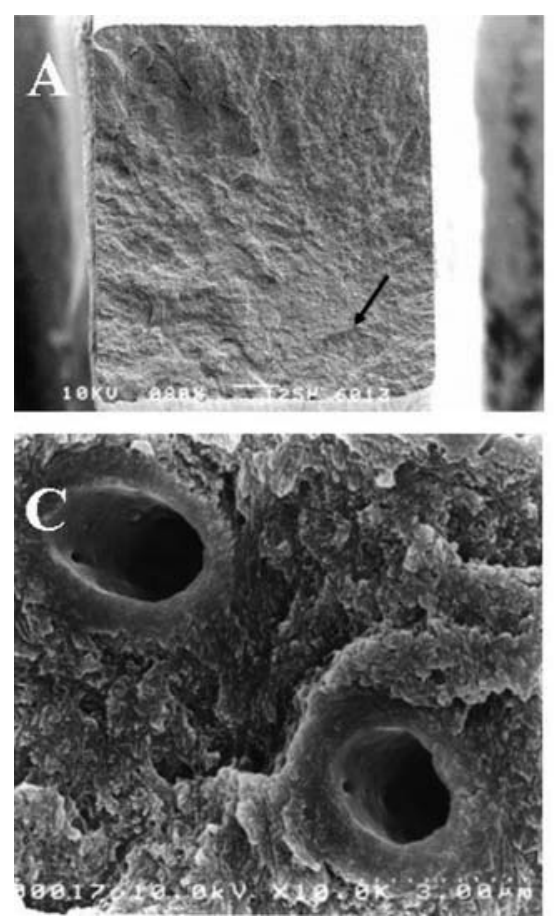
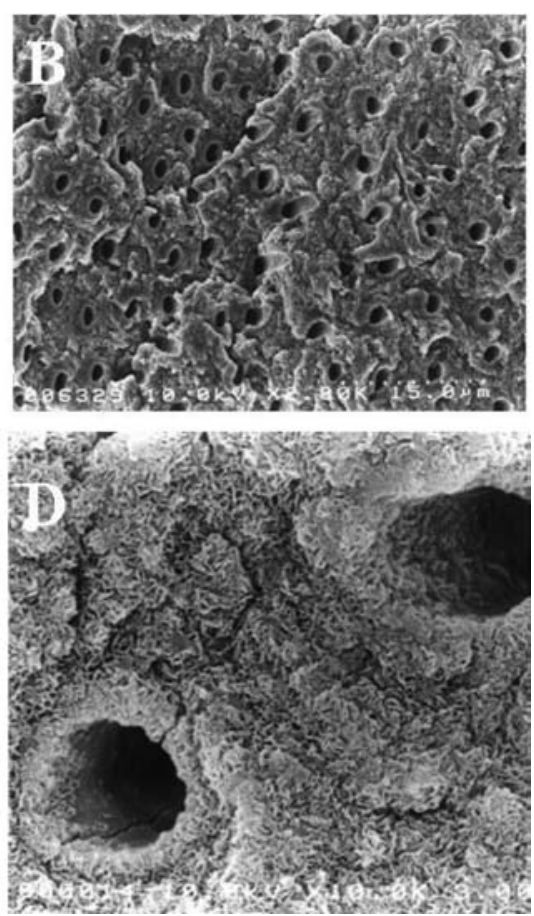

Fig. 4 (A) Typical fracture surface after tensile test (magnification $\times 100$ ).

(B) Typical fracture surface after tensile test (magnification $\times 2,000$ ).

(C) Typical fracture surface after tensile test (magnification $\times 10,000$ ).

(D) Dentinal tubules after treatment with boiling water for 45 minutes (magnification $\times 10,000)$.
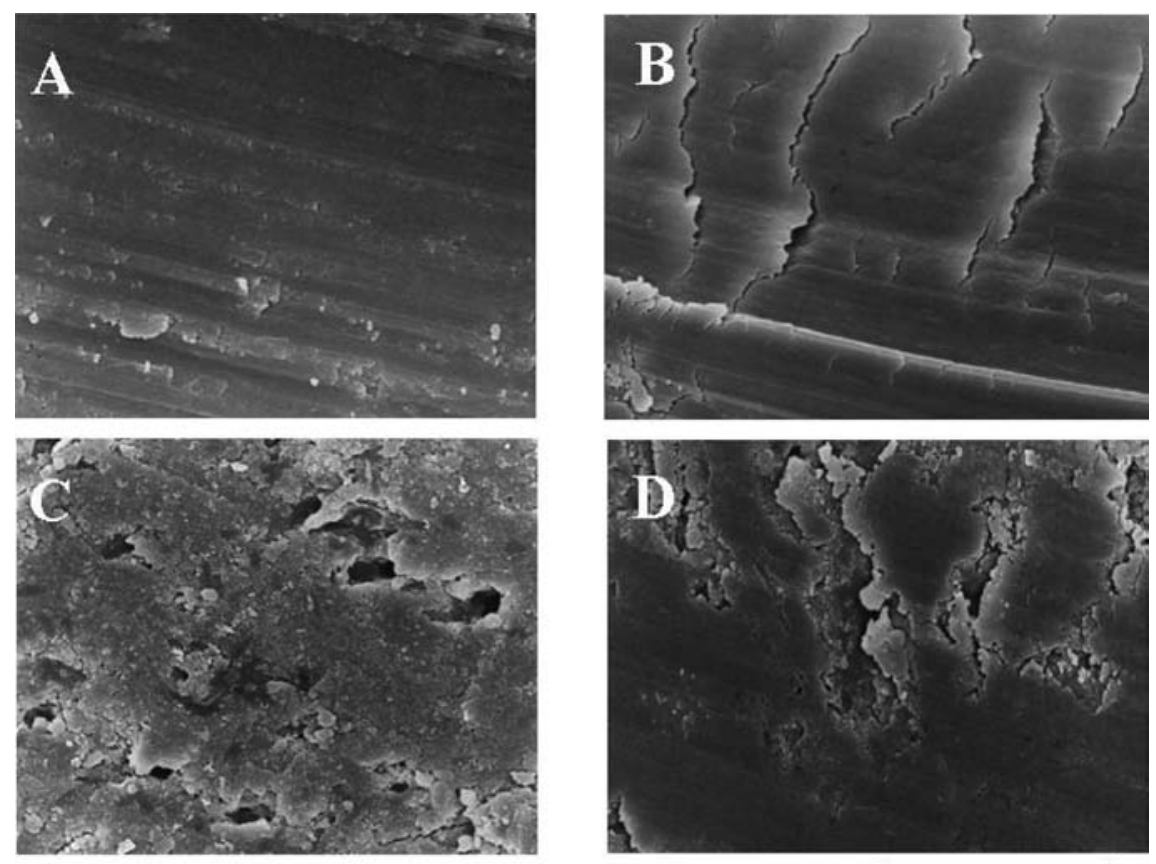

$10.0 \mu \mathrm{m}$

Fig. 5 (A) Fracture side surface as control.

(B, C) Fracture side surface after 10,000 thermal cycles in water.

(D) Fracture side surface after 10,000 thermal cycles in PBS. 
the specimens, those of the control (Group 1), after 10,000 thermal cycles in water (Group 2) and in PBS (Group 3) are shown in Fig. 5. The surfaces were covered by a smear layer. For water and PBS immersion groups (Figs. 5B and 5D), the images confirmed that their surfaces had cracked. Furthermore, after 10,000 thermal cycles in water (Fig. 5C), the smear layer was partially detached from the surface and dentinal tubules were seen.

\section{DISCUSSION}

In the present study, the tensile strength of bovine dentin did not significantly change after thermal cycling or storage in PBS and water at all tested temperatures, but decreased after 45 minutes of heating in boiling water. For the durability test of teeth using laboratory thermal cycling, the number of cycles typically ranges from 1 to $1,000,000$ cycles, with a provisional estimated mean of about 10,000 cycles ${ }^{14)}$. Moreover, it has been reported that 10,000 thermal cycles corresponds to three years in the human oral environment ${ }^{28)}$. Therefore, 10,000 cycles were performed in this study.

It was also reported that dentin adhesion was greater when samples were stored at a lower temperature ${ }^{29}$. To clarify the effect of temperature on dentin, specimens in this study were thus stored at $55^{\circ} \mathrm{C}$ and $5^{\circ} \mathrm{C}$ (Groups 4 and 5 versus Groups 8 and 9, respectively). However, it was found that temperature did not affect the tensile strength of dentin. In the same vein, specimens were also tested after heating in a boiling water bath for 45 minutes. This was because nuclear magnetic resonance (NMR) and differential thermal analysis (DTA) showed that dentin collagen became completely denatured in boiling water ${ }^{30)}$. Indeed, dentin tensile strength decreased after boiling, thus confirming that the profile of collagen influenced the tensile strength of dentin.

In the field of dental research, studies have been undertaken to evaluate the characteristics of hard dental tissues from several animal species with a view to substituting the human teeth ${ }^{31-33}$. Among the animal species evaluated, bovine teeth have been shown to be a good substitute for human teeth ${ }^{31-33}$. As such, bovine teeth were selected for this study. In addition, bovine dentin was chosen as the substrate because of the convenient size of the teeth. Based on the results obtained in this study, the tensile strength of bovine dentin did not change after thermal cycling. In other words, this could be likewise suggested for human dentin as bovine dentin is easier to demineralize than human dentin ${ }^{34}$. Hence, it could be conservatively presumed that a lesser effect would be observed with human dentin.

It was reported that dentin surfaces were demineralized after 10,000 thermal cycles in water - and as a result, there was a large decrease in the elastic modulus of dentin in water ${ }^{20)}$. On the other hand, dentin was not demineralized in PBS because the calcium ions in PBS prevented dentin demineralization ${ }^{35,36)}$. However, in the present study, no significant differences in tensile strength were observed between the water and PBS groups after 10,000 thermal cycles. Any micro-morphological changes that occurred in the surface during thermal cycling were very little and thus there were no differences in tensile strength.

At this juncture, it should be highlighted that over the span of several years, several thousands or tens of thousands of thermal cycles might occur in $v i v o^{1)}$. Expectedly then, dentin tensile strength would become weaker with time, albeit very slowly. Nonetheless, for the accelerated aging test in the present study, dentin strength was not affected by thermal stress after two weeks of water storage or 10,000 thermal cycles.

The Weibull plots of all the groups were very similar with a good linear relationship. Thus, a single fracture mode was assumed for all the groups. However, the Weibull modulus had a tendency to decrease with water immersion (Groups 2, 4, 6, and 8) as compared to PBS immersion groups (Groups 3, 5, 7, and 9); a low Weibull modulus value indicates a large scattering of the observed strength. Therefore, it was possible that water immersion caused a large scattering of dentin strength results, suggesting that dentin was affected by water storage. To avoid this adverse effect on dentin due to water storage, it was thus recommended that tooth specimens be thermal cycled between $5^{\circ} \mathrm{C}$ and $55^{\circ} \mathrm{C}$ in PBS solution.

\section{CONCLUSION}

The null hypothesis of this in vitro study was rejected. In other words, the mechanical properties of dentin were not affected by thermal stress arising from water storage at different temperatures for two weeks or due to 10,000 thermal cycles.

\section{ACKNOWLEDGEMENTS}

This work was supported by a Grand-in-Aid for Encouragement of Young Scientists (B), No. 17791408, from the Ministry of Education, Culture, Sports, Science and Technology of Japan.

\section{REFERENCES}

1) Lloyd BA, McGinley MB, Brown WS. Thermal stress in teeth. J Dent Res 1978; 57:571-582.

2) Brown WS, Jacobs HR, Thompson RE. Thermal fatigue in teeth. J Dent Res 1972; 51:461-467.

3) Spierings TA, Peters MC, Bosman F, Plasschaert AJ. Verification of theoretical modeling of heat 
transmission in teeth by in vivo experiments. J Dent Res 1987; 66:1336-1339.

4) Palmer DS, Barco MT, Billy EJ. Temperature extremes produced orally by hot and cold liquids. J Prosthet Dent 1992; 67:325-327.

5) Paphangkorakit J, Osborn JW. The effect of pressure on a maximum incisal bite force in man. Arch Oral Biol 1997; 42:11-17.

6) Paphangkorakit J, Osborn JW. Effects on human maximum bite force of biting on a softer or harder object. Arch Oral Biol 1998; 43:833-839.

7) Borcic J, Anic I, Smojver I, Catic A, Miletic I, Ribaric SP. 3D finite element model and cervical lesion formation in normal occlusion and in malocclusion. $\mathrm{J}$ Oral Rehabil 2005; 32:504-510.

8) Goel VK, Khera SC, Singh K. Clinical implications of the response of enamel and dentin to masticatory loads. J Prosthet Dent 1990; 64:446-454.

9) Dejak B, Mlotkowski A, Romanowicz M. Finite element analysis of stresses in molars during clenching and mastication. J Prosthet Dent 2003; 90:591-597.

10) Staninec M, Nalla RK, Hilton JF, Ritchie RO, Watanabe LG, Nonomura G, Marshall GW, Marshall SJ. Dentin erosion simulation by cantilever beam fatigue and $\mathrm{pH}$ change. J Dent Res 2005; 84:371-375.

11) Mishra P, Palamara JE, Tyas MJ, Burrow MF. Effect of loading and $\mathrm{pH}$ on the subsurface demineralization of dentin beams. Calcif Tissue Int 2006; 79:273-277.

12) Carlen A, Borjesson AC, Nikdel K, Olsson J. Composition of pellicles formed in vivo on tooth surfaces in different parts of the dentition, and in vitro on hydroxyapatite. Caries Res 1998; 32:447-455.

13) Ruhl S, Rayment SA, Schmalz G, Hiller KA, Troxler RF. Proteins in whole saliva during the first year of infancy. J Dent Res 2005; 84:29-34.

14) Gale MS, Darvell BW. Thermal cycling procedures for laboratory testing of dental restorations. J Dent 1999; 27:89-99.

15) Gwinnett AJ, Yu S. Effect of long-term water storage on dentin bonding. Am J Dent 1995; 8:109111.

16) Sano H, Takatsu T, Ciucchi B, Horner JA, Matthews WG, Pashley DH. Nanoleakage: leakage within the hybrid layer. Oper Dent 1995; 20:18-25.

17) Armstrong SR, Keller JC, Boyer DB. The influence of water storage and C-factor on the dentin-resin composite microtensile bond strength and debonded pathway utilizing a filled and unfilled adhesive resin. Dent Mater 2001; 17:268-276.

18) Vijayaraghavan TV, Hsiao J. Flexural behavior of visible light-cured composites as a function of temperature under water immersion test conditions. Dent Mater 1994; 10:347-352.

19) Santerre JP, Shajii L, Leung BW. Relation of dental composite formulations to their degradation and the release of hydrolyzed polymeric-resin-derived products. Crit Rev Oral Biol Med 2001; 12:136-151.

20) Habelitz S, Marshall GW Jr, Balooch M, Marshall
SJ. Nanoindentation and storage of teeth. J Biomechanics 2002; 35:995-998.

21) Tonami K, Takahashi H, Nishimura F. Effect of frozen storage and boiling on tensile strength of bovine dentin. Dent Mater J 1996; 15:205-211.

22) Tonami K, Takahashi H. Effects of aging on tensile fatigue strength of bovine dentin. Dent Mater J 1997; 16:156-169.

23) Nakano F, Takahashi H, Nishimura F. Reinforcement mechanism of dentin mechanical properties by intracanal medicaments. Dent Mater J 1999; 18:304-313.

24) Inoue $\mathrm{T}$, Takahashi $\mathrm{H}$, Nishimura F. Anisotropy of tensile strengths of bovine dentin regarding dentinal tubule orientation and location. Dent Mater J 2002; 21:32-43.

25) Tonami K, Takahashi H, Kato J, Nakano F, Nishimura F, Takagi Y, Kurosaki N. Effects of laser irradiation on tensile strength of bovine dentin. Photomed Laser Surg 2005; 23:278-283.

26) Tonami K. Effects of aging on tensile strength of bovine dentin. J Jpn Dent Mater 1997; 16:187-196.

27) Nakano F. Effect of intracanal medicaments on mechanical properties of bovine dentin. J Jpn Dent Mater 1999; 18:128-136.

28) Miyazaki T, Suzuki E, Miyaji T. The influence of thermal cycling on the mechanical properties of posterior restorative composite resins. J J Dent Mater 1986; 5:187-195.

29) Leloup G, D'Hoore W, Bouter D, Degrange M, Vreven J. Meta-analytical review of factors involved in dentin adherence. J Dent Res 2001; 80:1605-1614.

30) Ito H, Nezu T, Fukuda K, Nagadome H, Terada Y. Effects of denaturation of dentinal proteins on adhesion - Strength of resin-impregnated layer model. J Jpn Prosthodont Soc 1997; 41:910-914.

31) Fonseca RB, Haiter-Neto F, Fernandes-Neto AJ, Barbosa GA, Soares CJ. Radiodensity of enamel and dentin of human, bovine and swine teeth. Arch Oral Biol 2004; 49:919-922.

32) Schilke R, Bauss O, Lisson JA, Schuckar M, Geurtsen W. Bovine dentin as a substitute for human dentin in shear bond strength measurements. Am J Dent 1999; 12:92-96.

33) Nakamichi I, Iwaku M, Fusayama T. Bovine teeth as possible substitutes in the adhesion test. J Dent Res 1983; 62:1076-1081.

34) Arao T, Nakabayashi N. Effect of miniaturized dumbell-shaped specimen to identify bonding of bovine dentin. J Jpn Dent Mater 1997; 16:175-181.

35) Takagi S, Chow LC, Sieck BA. Deposition of loosely bound and firmly bound fluorides on tooth enamel by an acidic gel containing fluorosilicate and monocalcium phosphate monohydrate. Caries Res 1992; 26:321-327.

36) Chow LC, Takagi S, Frukhtbeyn S, Sieck BA, Parry EE, Liao NS, Schumacher GE, Markovic M. Remineralization effect of a low-concentration fluoride rinse in an intraoral model. Caries Res 2002; 36:136141. 